\title{
Delamination Analysis of Fly Drop-Off in Tapered Laminated Composite
}

\author{
Gaurav Chaudhary ${ }^{\# 1}$, Abhijit Dey ${ }^{\# 2}$, Amit kumar Dey $^{* 3}$, Subhankar Das ${ }^{\# 4}$ \\ \#Department of Mechanical engineering, National Institute of Technology, Silchar, Assam, India,788010 \\ *Dept. of Civil engineering, Central Institute of Technology, Kokrajhar, Assam,India \\ 'gaurav.chaudhary.coer@gmail.com \\ 2aad.mec.abhi@gmail.com \\ *ak.dey@cit.ac.in \\ ${ }^{4}$ subha.me31@gmail.com
}

\begin{abstract}
Thickness variation in tapered laminates obtained by terminating a certain number of plies contains resin-rich areas called 'resin pockets' near ply drops, where high stress concentrations exist. the effects of single step and consecutive fly drops on the tensile behaviour of tapered laminates considering certain important parameters like taper angle, the number of plies dropped, and the fiber orientation is reported here.Tsai-Wu failure criterion is successfully implemented to find the failure factor for selective plies. The mechanism of load transfer near ply drops and the local bending are discussed in details.High stress concentration occurs at near to the tip of epoxy region. In different fibre orientation for dropped plies, the $90^{0}-90^{0}$ orientation gives minimum value of longitudinal stress.
\end{abstract}

Keywords: Ply-Drop, Interlaminar stress, Delamination, ANSYS.

\section{INTRODUCTION}

Tapered laminated structures, in which ply drop at discrete positions shows structural tailoring capabilities damage tolerance with potential for weight saving in engineering application. Most of the times ply drop has been occurmore than one directional in laminated structural components [1]. Due to termination of plies at certain planar locations, causes ply drop. Ply termination causes rise in stress concentration leads to reduction in laminate strength. High interlaminar stress may lead to defect like delamination [2]. However, many researcher has been studied the mechanism behind the different fly-drop configurations.Curry et al.[3]analysed 16 ply graphite epoxy laminates with four plies dropped at the midplane using a two stage finite element technique. An experimental study of the same laminate shows failure analysis under predicted failure load was significantly about 33\%.Shiuh-Chuan Her [4]described a combination of analytical and numerical method to solve the plydrop off problemby using Eigen function expansion method.Morton et al. [5] proposed a simple method for the design and assessment of tapered laminates.Weicheng Cui et al. [6]studied of step spacing and found that small step spacing create significant effect on delamination stress, however, when the spacing is grater then certain value, the effect is negligible. They compared two extreme cases where delamination stress varies by $27 \%$.

It has been observedthat the strength of the tapered laminate composites by finite element technique was considering a superior approach to demonstrate the ply drops as it brings out the areas of stress concentrations [7-10]. Inthis study 3-D solid element has been consider instead of 2-D finite elements because of usefulness for taper laminate model construction.But conventional 3-D FE analysis becomes very costly in terms of computational resources as the number of plies increases. Hence, layered 20-noded solid elements are used to model such laminates which significantly reduce the computational effort.A typical ply-drop configuration of a taper laminate beam is shown in Fig.1 (a).

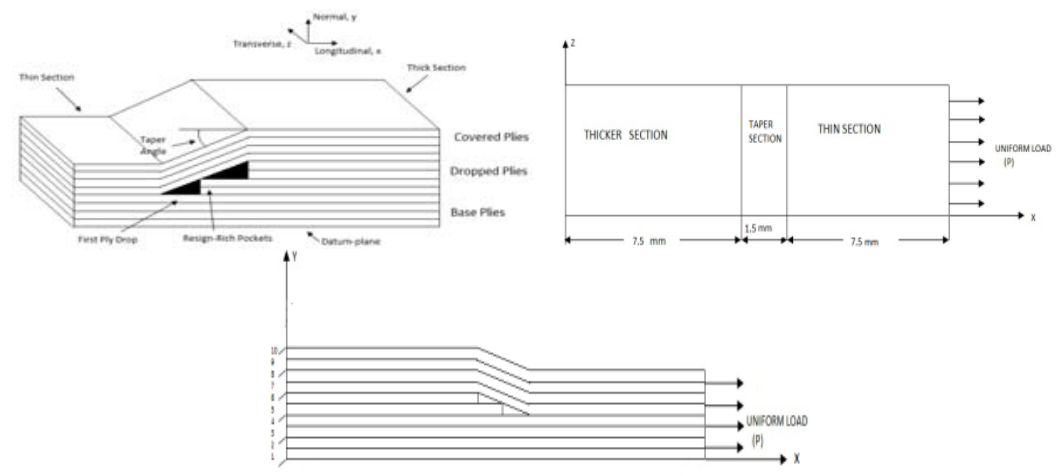

Fig.1(a) Ply-Drop Configuration of taper laminate beam. (b) Top view of model (c) Ply-Drop in consecutive step 


\section{Models Description}

In present study two different ply drop configurations, single step drop and consecutive drop $\left[0_{4} / \theta_{2 \mathrm{D}} / 0_{4}\right]$ considered are shown in Fig.1 (b) and(c) respectively. Middle two plies are dropped and rest plies run continuously in $\mathrm{x}$ direction. For both configurations constant parameters are length of the laminate, thick and thin section, and taper angle .For dropped plies different layup configuration considered with remaining all plies are at $0^{0}$ fibre orientation. Taper angle for all configuration considered $\alpha=11.3^{0}$.CFRP material is taken for analysis. Table 1and 2 shows properties of CFRP ply material and Epoxy respectively. Length of thick and thin section is $7.5 \mathrm{~mm}$ respectively and taper section length is $1.5 \mathrm{~mm}$. The displacement and the force boundary conditions chosen as follows:

$\mathrm{u}=0$ at $\mathrm{X}=0 ; \mathrm{v}=0$ at $\mathrm{Y}=0$ andw $=0$ at $\mathrm{Z}=0$ and uniform pressure at $\mathrm{X}=\mathrm{L}$ on $\mathrm{Y}-\mathrm{Z}$ plane $\left(\sigma_{0}=350 \mathrm{MPa}\right)$.

All the cases datum for numbering the plies is $\mathrm{Y}=0$ plane.

\section{FINITE ELEMENT ANALYSIS}

Finite Element Method (FEM) was used to predict the delamination behaviour of the configured drop-flys.In the present aspect, only one element is used to model in z direction so there is no variation of stresses in the width. Failure load factor, using Tsai-Wu failure criterion given below which takes into consideration all the six component of stress and strength, are determine for different fibre orientation.

$\mathrm{f}=\mathrm{H}_{1} \sigma_{1}+\mathrm{H}_{2} \sigma_{2}+\mathrm{H}_{3} \sigma_{3}+\mathrm{H}_{12} \sigma_{1} \sigma_{2}+\mathrm{H}_{23} \sigma_{2} \sigma_{3}+\mathrm{H}_{13} \sigma_{1} \sigma_{3}+\mathrm{H}_{11} \sigma_{1}{ }^{2}+\mathrm{H}_{22} \sigma_{2}{ }^{2}+\mathrm{H}_{33} \sigma_{3}{ }^{2}+\mathrm{H}_{44} \sigma_{4}{ }^{2}+\mathrm{H}_{55} \sigma_{5}{ }^{2}+\mathrm{H}_{66} \sigma_{6}{ }^{2}$

Where,

$\mathrm{H}_{1}=\frac{1}{\mathrm{X}_{\mathrm{T}}}-\frac{1}{\mathrm{X}_{\mathrm{C}}} ; \quad \mathrm{H}_{2}=\frac{1}{\mathrm{Y}_{\mathrm{T}}}-\frac{1}{\mathrm{Y}_{\mathrm{C}}} ; \quad \mathrm{H}_{3}=\frac{1}{\mathrm{Z}_{\mathrm{T}}}-\frac{1}{\mathrm{Z}_{\mathrm{C}}} ; \quad \mathrm{H}_{11}=\frac{1}{\mathrm{X}_{\mathrm{T}} \mathrm{X}_{\mathrm{C}}} ; \quad \mathrm{H}_{22}=\frac{1}{\mathrm{Y}_{\mathrm{T}} \mathrm{Y}_{\mathrm{C}}} ; \mathrm{H} 33=\frac{1}{\mathrm{Z}_{\mathrm{T}} \mathrm{Z}_{\mathrm{C}}} ; \mathrm{H} 44=\frac{1}{\mathrm{~S}_{\mathrm{XY}}^{2}} ;$

$\mathrm{H}_{55}=\frac{1}{\mathrm{~S}_{\mathrm{YZ}}^{2}} ; \mathrm{H}_{66}=\frac{1}{\mathrm{~S}_{X Z}^{2}} ; \mathrm{H}_{12}=\frac{1}{2} \sqrt{\mathrm{H}_{11} \mathrm{H}_{22}} ; \quad \mathrm{H}_{23}=\frac{1}{2} \sqrt{\mathrm{H}_{22} \mathrm{H}_{33}} ; \mathrm{H} 13=\frac{1}{2} \sqrt{\mathrm{H}_{11} \mathrm{H}_{33}} ;$

and, $\left\{\sigma_{1} \sigma_{2} \sigma_{3} \sigma_{4} \sigma_{5} \sigma_{6}\right\}=\left\{\sigma_{\mathrm{xx}} \sigma_{\mathrm{yy}} \sigma_{\mathrm{zz}} \tau_{\mathrm{xy}} \tau_{\mathrm{yz}} \tau_{\mathrm{xz}}\right\}$

Hexagonal mesh is taken in analysis.All plies are taken with $0^{0}$ orientations. The result indicate good convergence trend and small element size 0.0625 is chosen along X direction for all subsequent study.

\section{STRESS DISTRIBUTION FOR LAMINATE DUE TO TAPER}

Fig. 4 shows the contour of in-plane stress along the $\mathrm{X}$ axis. Maximum value of $\sigma_{\mathrm{x}}, \sigma_{\mathrm{y}}$, and $\tau_{\mathrm{xy}} \mathrm{occur}$ at near the taper zone. The base ply near the drop ply has maximum longitudinal stress at the tip of epoxy triangular section. Transverse stress is varying negative to positive along the edge of epoxy region. Positive transverse stress is maximum at the tip of epoxy region which indicate ply delamination chance at the tip ismore. Negative transverse stress was retainingat the end edge of dropped plies.Fig.4(a),(b) and(c)shows transverse stress inconsecutive drop condition. In case of consecutive ply drop, the tip which is near to thin section of epoxy region shows maximum stress concentration. For longitudinal stress at last covered ply shows maximum value due to local bending effect of laminate.

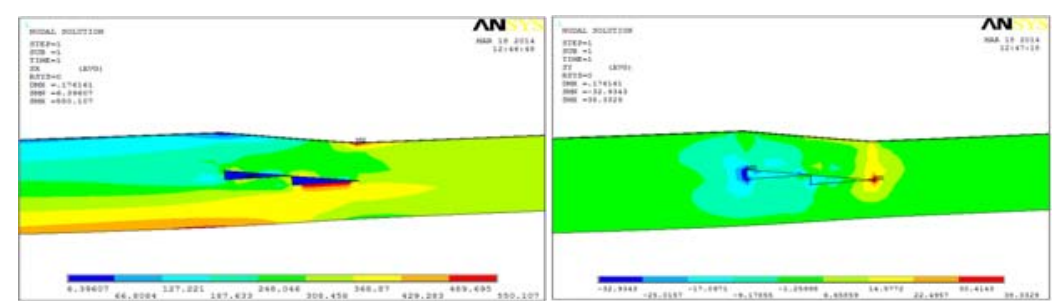

(a)

(b)

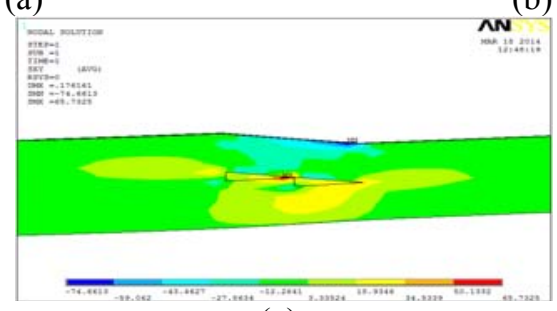

(c)

Fig.4 Stress counter for single step and consecutive drop with $\left[0_{4} / \theta_{\mathrm{D} 2} / 0_{4}\right](\mathrm{a}, \mathrm{b})$ Longitudinal Stress X direction (c, d) Normal Stress Y direction (e, f) Shear Stress X-Y plane. 


\section{STRESS DISTRIBUTION FOR CONSECUTIVE DROP}

For the study selective plies are considered which are near drop region. Ply 4 is a base ply, Ply 5 and 6 are dropped plies, ply 7 and 10 are covered plies are chosen. In cases ply 4, at the tip of epoxy region $(9 \mathrm{~mm})$ maximum longitudinal stress is found. At the beginning of first epoxy pocket $(8.25 \mathrm{~mm})$ stress, slightly drop then increases .For both drop plies 5 and 6 longitudinal stress decreasing up to end and at end point small increment is considered.In ply 7 longitudinal and inter laminar stress is maximum at tip of epoxy region. At ply 10 maximum longitudinal stresses is found at end of taper portion $(9 \mathrm{~mm})$ due to local bending effect.

Ply 4
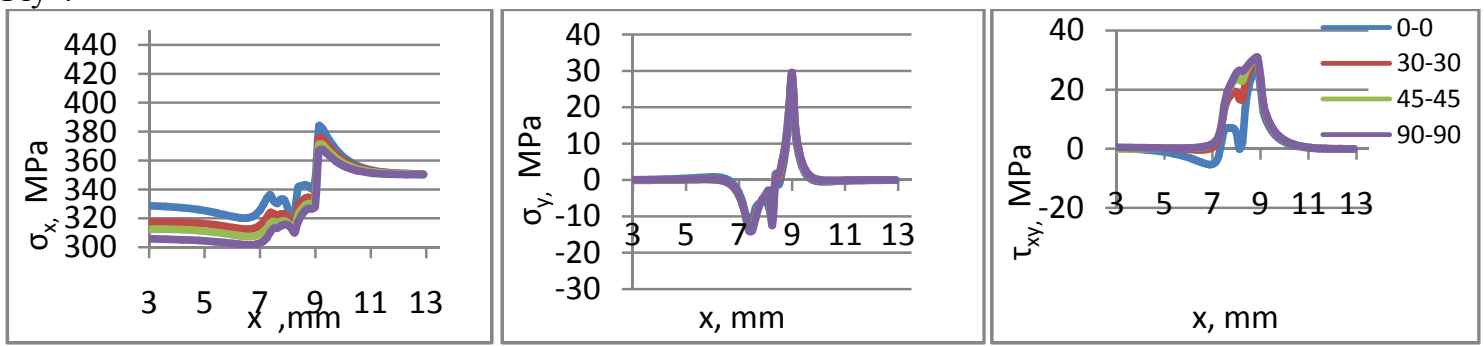

Ply 5
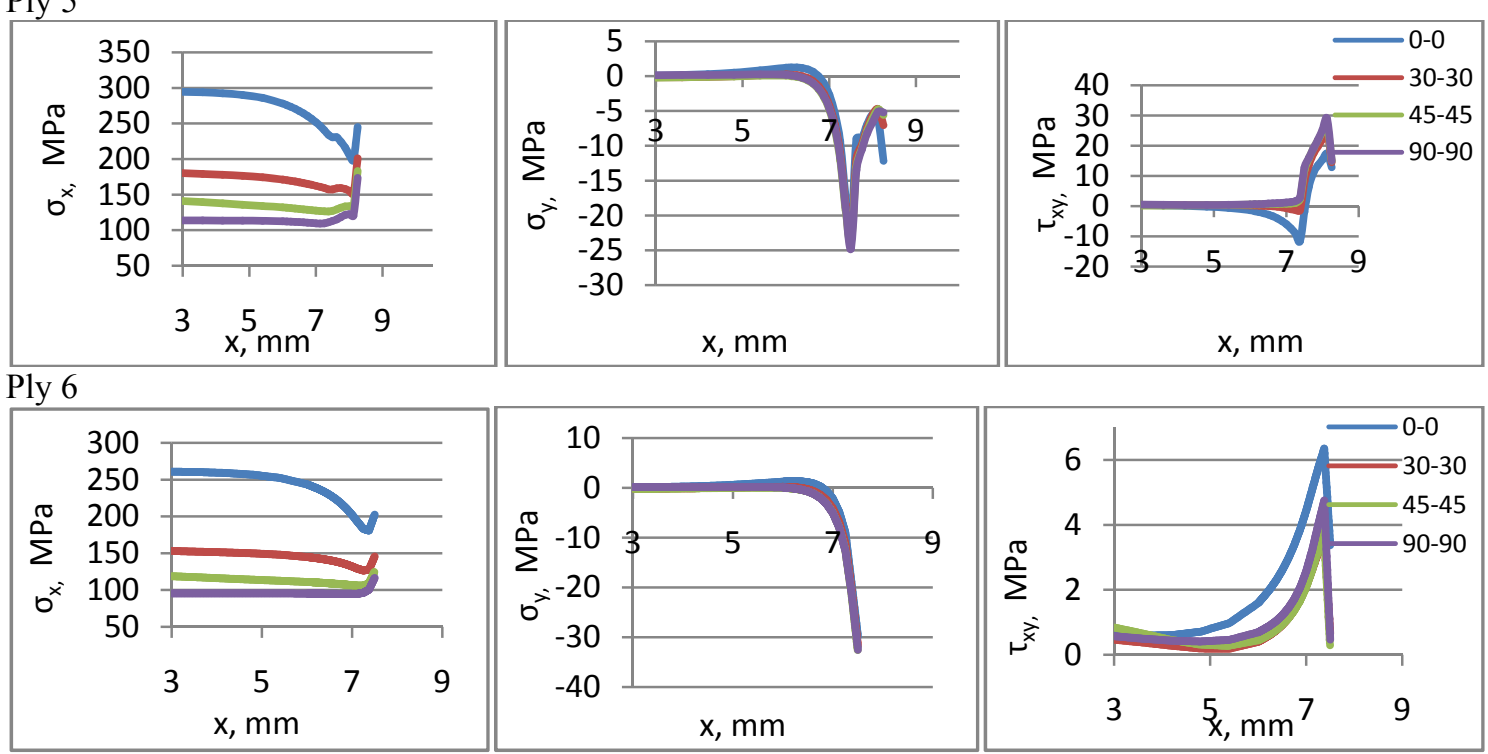

Ply 7
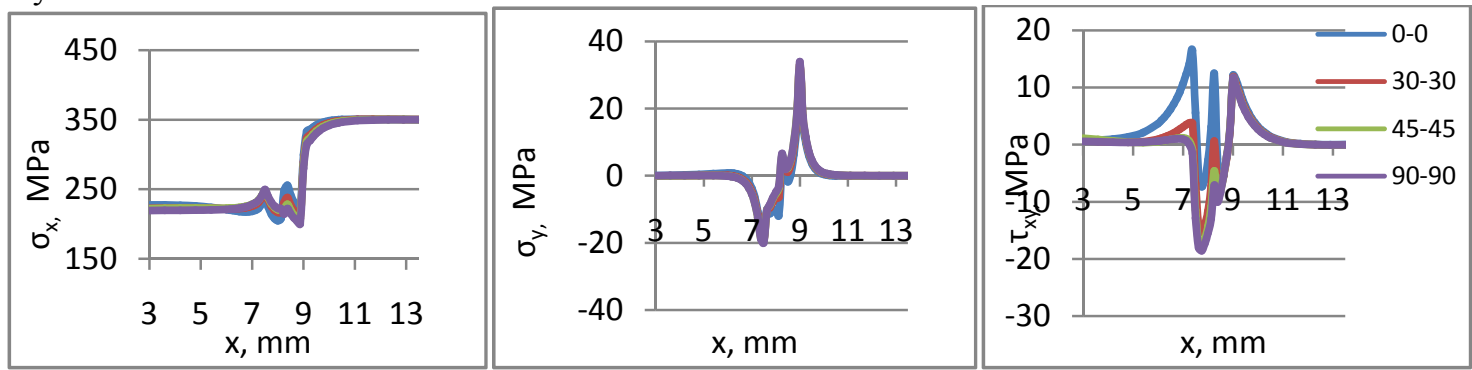

Ply 10
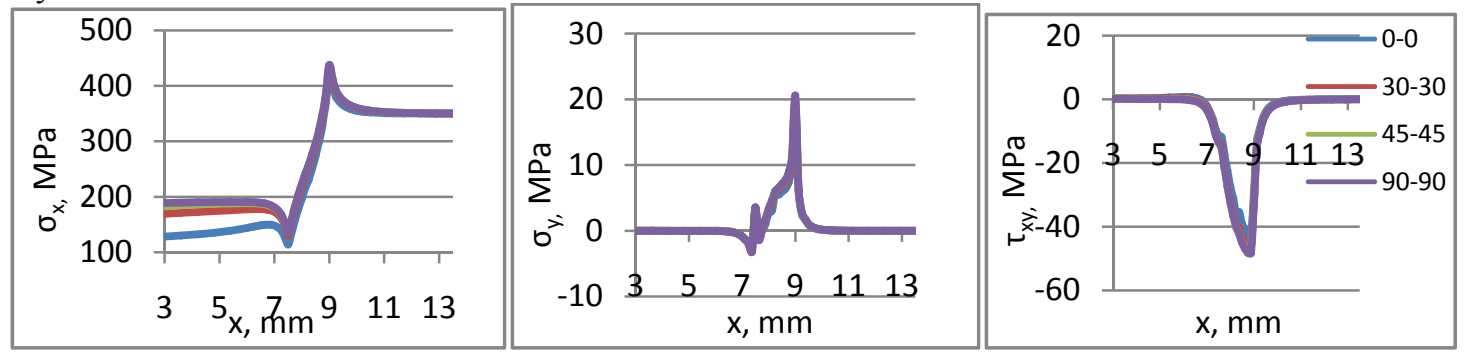

In above trends stress distribution in different plies for both configurations with different drop plies orientation is shown.It is found at $90-90$ orientation longitudinal stress comes minimum but inters laminar stresses $b_{\mathrm{y}}, \tau_{\mathrm{xy}}$ become higher that mean for 90-90 ply delamination chances are maximum. 


\section{INTER LAMINAR STRESS DISTRIBUTION WITH THICKNESS OF LAMINATE AND DELAMINATION PREDICTION}

Variation of interlaminar stress with thickness of laminate is shown in Fig.5. Itwas observed that at the tip of epoxy region, normal stress is maximum and positive and the drop plies position it is negative shows that delamination will always start at tip.In case of consecutive ply drop first epoxy region, which is near to the thin section at its tip normal stress is maximum and positive that's mean delamination is, always start at that epoxy tip which is near to the thin section.

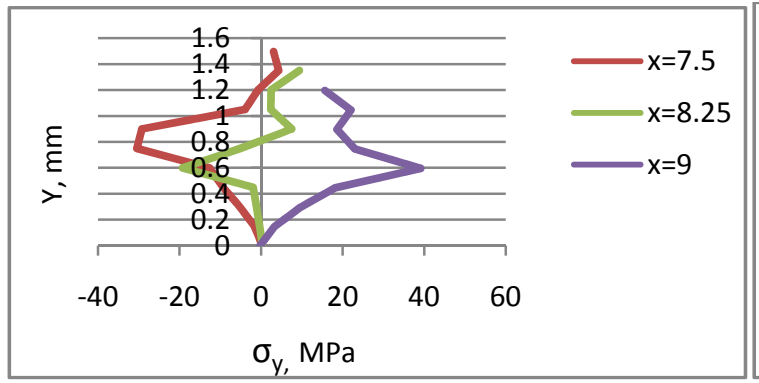

(a)

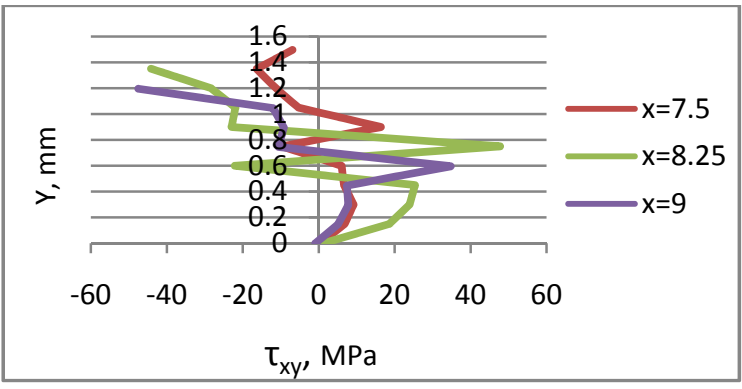

(b)

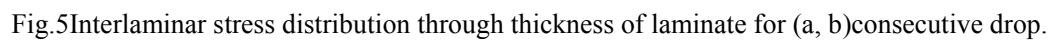

Fig.6 shows the inter laminar stress distribution at the taper site along ply length .It is found at the junction of base ply and epoxy region,normalstress near the tip is greater than junction of covered ply and epoxy.It shows that delamination probability to propagate with base ply is high.

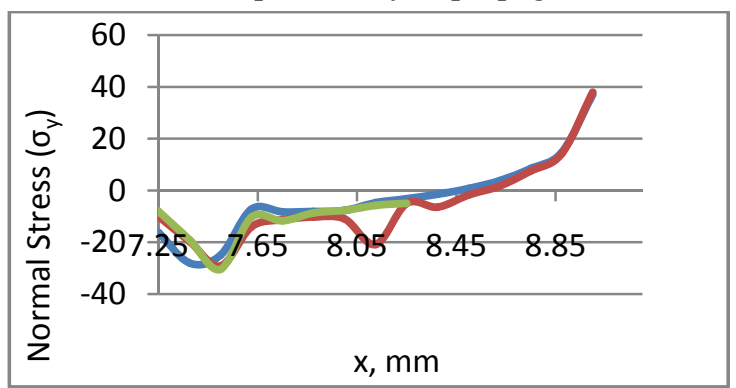

(a)

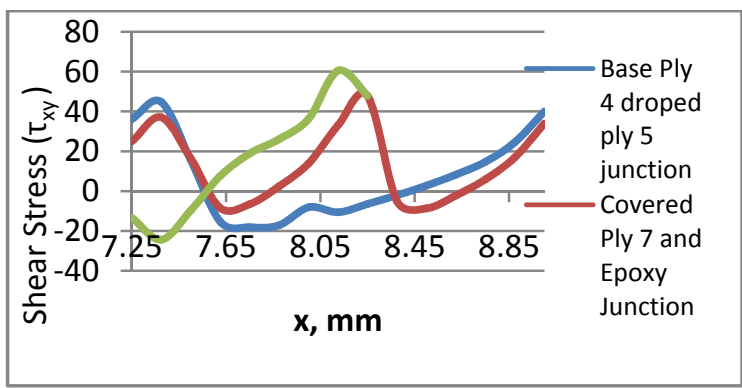

(b)

Fig.6 Inter laminar Stress variation at the epoxy site for ( $a, b)$ consecutive drop.

\section{FAILURE FACTOR FOR SELECTIVE PLIES USING TSAI-WU CRITERION}

In Fig.7 failure factor for selective plies are shown using Tsai-Wu criterion. It is found that failure factor at the end of drop plies is greater in single step drop. At the tip of epoxy region both covered and base plies failure factor is maximum. Failure factor increases at ply termination site due to shear-lag and load is delivered to continuous plies from dropped plies

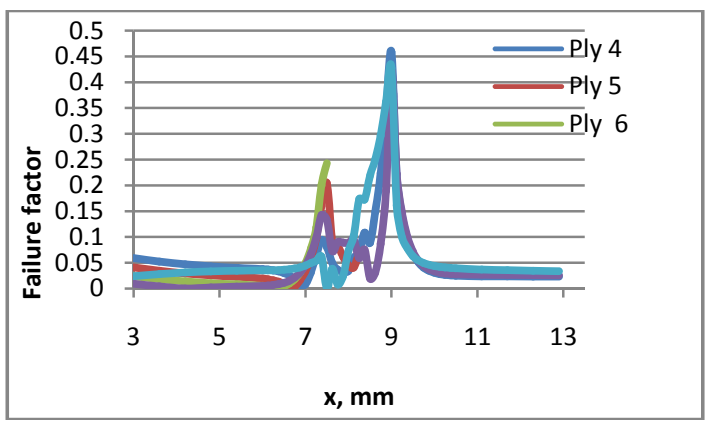

Fig. 7 Failure factor for taper laminate $\left[0_{4} / \theta_{2 \mathrm{D}} / 0_{4}\right]$ consecutive drop. 


\section{CONCLUSION}

In the present study, stress analysis and delamination prediction is investigated for taper laminate composite with consecutive fly-drop. Tsai Wu criterion has successfully implementedfor failure analysis of different plies. Interlaminar stress is consideredfor delamination prediction. Following result has been summarised:

- High stressconcentration occurs at near to the tip of epoxy region is found.

- Longitudinal stress $\left(\sigma_{\mathrm{x}}\right)$ in different plies has been determined and found that at outer covered plies at the beginning of thin section stress is maximum due to bending effect.

- For $90^{\circ}-90^{\circ}$ orientation of drop ply longitudinal stress is minimum.

- Failure factor for selected plies near the tip of epoxy region is maximum which shows that chances of failure at tip is more.

- Consecutive drop normal stress is always occur maximum at the tip of epoxy region at near the thin section which shows that delamination chances is more.

\section{REFERENCES}

[1] B.R. Vidyashankar \& A.V. Krishna Murty,Analysis of laminate with ply drops, Composite Science and Technology. 61(5) (2001) 749758.

[2] Fish,J.C. \& Vizzini, A.J.,Delamination of ply-drop configurations,Composite Material Testing and Design.11(1993) 323-332.

[3] Curry JM, Johnson ER, Starnes Jr. JH.,Effect of dropped plies on the strength of graphite-epoxy laminates, In: Proc. of AIAA/ ASME/ASCE/AHS/ASC 29th Structures, Structural Dynamics, Materials Conf. Part I, Monterey, CA; AIAA paper No. 87-084 (1987) $737-47$.

[4] Shiuh-Chuan Her., Stress analysis of ply drop-off in composite structure,Composite Structures. 57 (2002) 235-244.

[5] Morton SK, Webber JPH, Thomas DM.,Design and Assessment of Composite Tapered Laminated Plates, AIAA. 5 (1994) $2763-73$.

[6] Weicheng Cui, Michael R. Wisnom \& Mike Jones.,Effect of step spacing on delamination of taper laminates, Composite Science \& Technology. 52 (1994) 39-46.

[7] Byji Varughese \& Mukherjee Abhijit, A ply drop-off element for analysis of tapered laminated composites, Composite Structure.39 (1997) 123-144.

[8] P.D. Mangalgiri \& K. Vijayaraju,An analytical study on 0/90 ply-drops in composite laminate", Composite Structure, 28(2) (1994) 181-185.

[9] Priyanka Dhurvey \& N.D. Mittal, Study the effect of externally and internally ply drop-off in composite laminate analysis, ARPN Journal of Engineering and Applied Science.8 (4) (2013).

[10] D.S.Cairns, J.F. Mandell \& M.E. Scott.,Design and manufacturing consideration for ply drops in composite, structures Composites: Part B. 30 (1999) 523-534. 